\title{
The Analysis of Muscle Performance on Softball Pitching Motion
}

\author{
Yudy Hendrayana*, Jajat Darajat K Negara, Agus Gumilar \\ School of Physical Education, Sport Education Department \\ Universitas Pendidikan Indonesia \\ *yudy_h2000@upi.edu
}

\begin{abstract}
Picthers play an important role in softball, especially when defending. Pitching is a high explosive motion involving both smooth and big muscles especially an upper limb. This study aimed to acquire data and empirical proof of muscle performance on learning softball pitching based on science through electromyography (EMG) sensor approach. The research method used in this study is descriptive quantitative with analytical survey. The sampling technique employed in this study is saturated sampling since the sample is all the population which are all members of UPI students' softball club. The results of the data analysis show that the muscle performance included the upper body (34\% pectoral, $28 \%$ bicepes, $17 \%$ deltoid, $14 \%$ latisimus dorsi, and $6 \%$ triceps), and lower body $(42 \%$ hamstring, $23 \%$ outer quadriceps, $19 \%$ inner quadriceps, and $16 \%$ glute) for the first session. For the second session, the results of the upper body are $34 \%$ pectoral, $31 \%$ biceps, $15 \%$ deltoid, $14 \%$ latisimus dorsi, and $6 \%$ triceps and those of the lower body are $41 \%$ hamstring, $25 \%$ quadricpes, $20 \%$ inner quadriceps, and $14 \%$ glute. Based on the results, it can be concluded that pitching learning have the most impact on pectoral and hamstring muscles.
\end{abstract}

Keywords—muscle performance; softball; pitching; picthing motion

\section{INTRODUCTION}

Pitching is a key movement influencing defensive softball games and giving significant contribution [1]. There are a lot of athletes actively involved in fast pitch softball, either men or women. However, in Indonesia, there is limited number of studies on muscle performance analysis. A study by Werner et al., proves that there are 2 million girls aged 12-18 actively involved in fast pitch softball [2]. Pitching with windmill has an injury risk when performed without the clear procedure. There are a few studies correlating the motion with muscle performance aiming at avoiding injury risks [2-4].

Previous studies mostly focus on biomechanics specifically explaining how to perform the pitching efficiently. Rarely did those previous studies discuss the muscle performance in pitching. A study by Argo reveals that an injury risk of pitching is quite huge since the windmill produced is high and that the risks it brings are also big, particularly on ulnar collegiate and medial elbow muscles [5]. Another study by Hill proves that there is a muscular injury on upper arms and forearms to young people between the age of high schools and that of college [6]. However, this is different with the results of a study by Meyer et al. finding that there is a big effort and power in windmill yet it does not focus on forearm muscles [7]. Furthermore, it has been also proven that in wind will, there are three fracture cases on the ulnar when performing windmill [8]. Different from baseball, the number of pitches in softball is a lot more than that in baseball. For instance, within a 3-day tournament, the pitchers perform $1200-1500$ pitches. However, in baseball, there are only 100-150 pitches within the same period. This number leads to the possibility of injury. In addition, Werner et al points out that there is a great potential of windmill pitching injuries analyzed through regression. However, this study did not implement electromyography (EMG) to analyze the activities of arm muscles [9].

Based on the aforementioned reasons, this paper intended to analyze muscular activities using an EMG sensor so that electrical signals can be reflected when doing pitching.

\section{METHOD}

The study used a descriptive quantitative survey design. The survey focused on the use of EMG sensor installed on a pitcher connected to an application to a smartphone through Bluetooth namely "Live Athos". The subjects of this study were all pitchers of UPI's softball student club. Each pitcher had to perform 25 pitches which would be recorded and analyzed descriptively. The data interpretation was based on previous study and in comparison among each pitch. The phases of windmill pitching are presented in Figure 1.

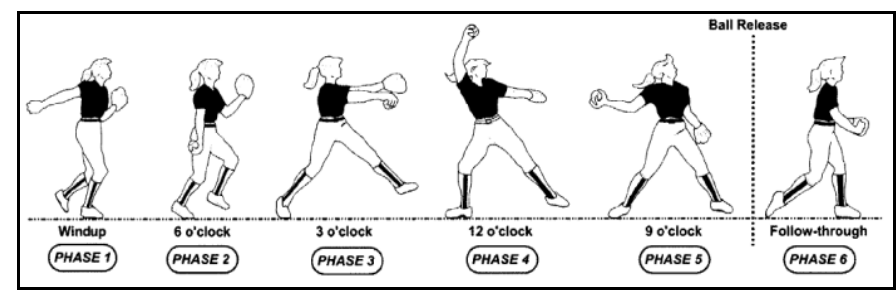

Fig. 1. Windmill pitching phases [10].

In this study, the pitchers' performance was analyzed based on EMG sensor in both upper body and lower body muscles. Thus, all the pitchers perform the motion as shown in Figure 1.

\section{RESULTS}

Figure 2 shows the muscular activities of an upper body from right to left performed by the first pitcher with the 
following muscles pectoralis $(12 \%-23 \%)$, biceps (13\%-15\%), deltoid (7\%-10\%), latisimus dorsi $(7 \%-7 \%)$, and triceps $(3 \%$ $3 \%)$, while those of the second pitcher are pectoralis $(12 \%$ $21 \%)$, biceps $(15 \%-16 \%)$, deltoid $(7 \%-9 \%)$, latisimus dorsi (7\%-7\%), and tricpes (3\%-3\%).

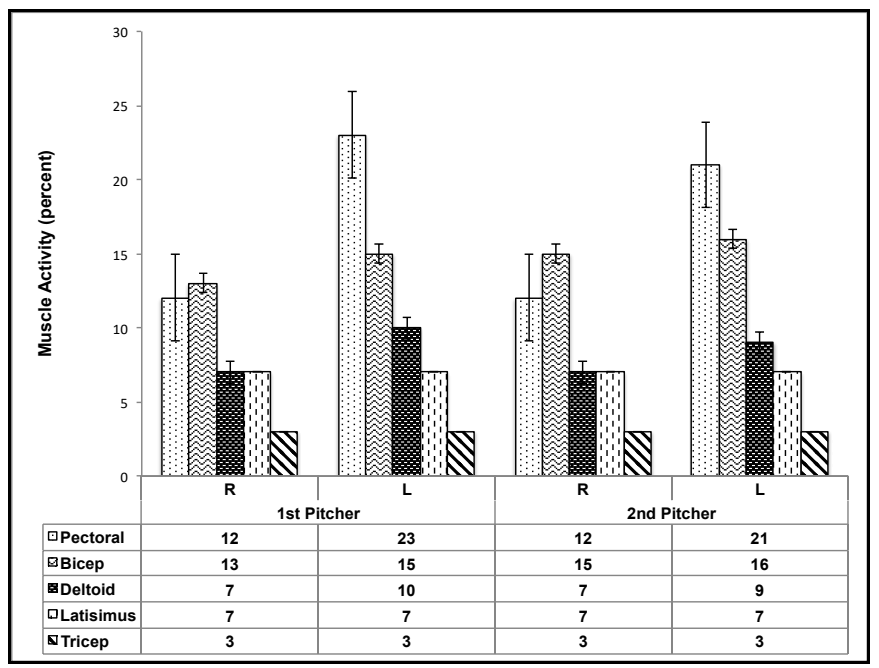

Fig. 2. Muscles activities on pitching windmill in upper body.

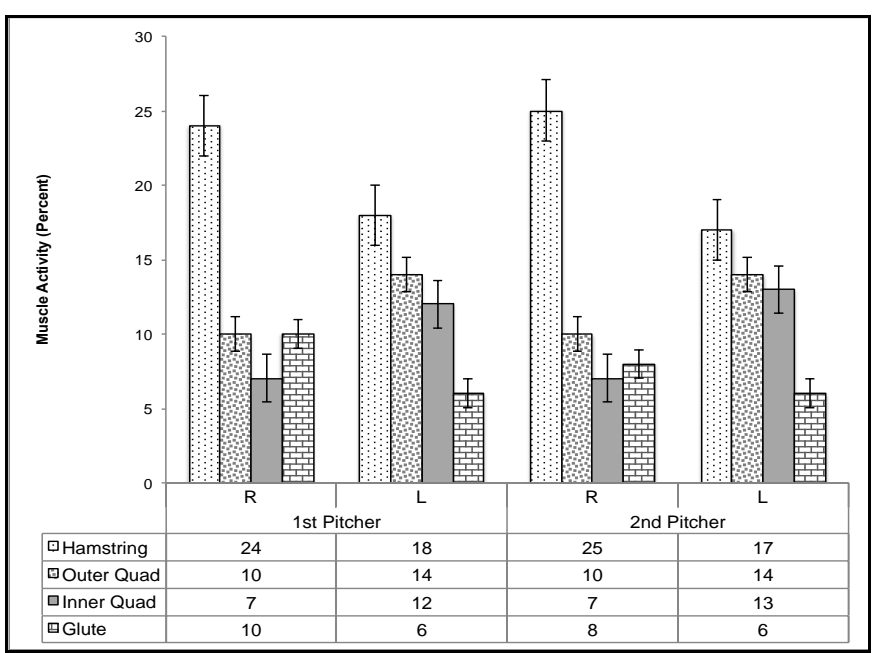

Fig. 3. Muscles Activities on pitching pitching windmill in lower body.

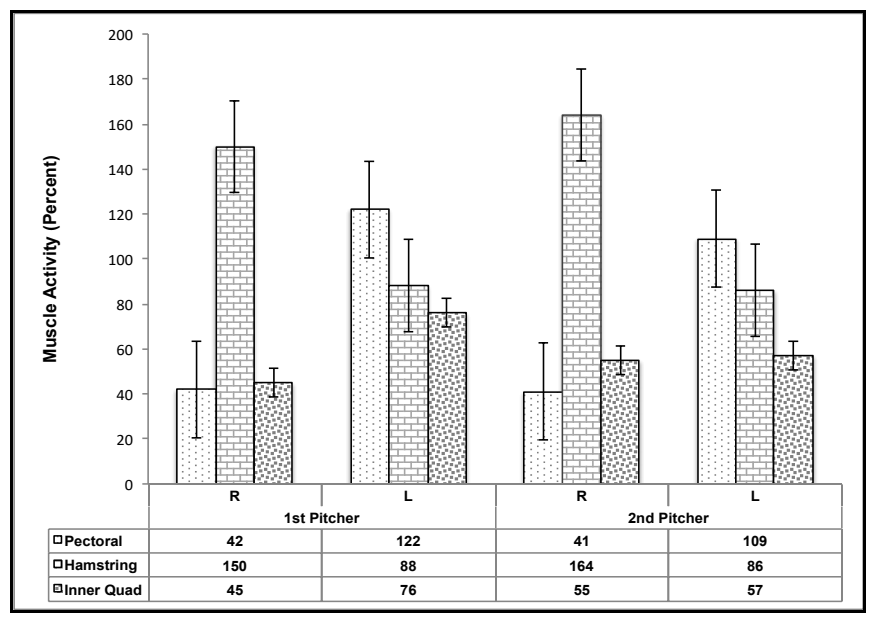

Fig. 4. Comparison of muscles activities on windmill pitching.
Figure 3 shows the muscular activities of a lower body from right to left. The activities of the first pitcher are hamstring (24\%-18\%), outer quadriceps $(10 \%-14 \%)$, inner quadriceps $(7 \%-12 \%)$, and glute $(10 \%-6 \%)$. In the meantime, the activities of the second pitcher are hamstring (25\%-17\%), outer quadiceps (10\%-14\%), inner quadiceps (7\%-13\%), and glute $(8 \%-6 \%)$.

Figure 4 shows the comparison of analytical results of maximum muscular activities among all muscles of both upper and lower body from right to left. The results of the first pitcher are pectoral (42\%-122\%), hamstring (150\%-88\%), and inner quadriceps $(45 \%-76 \%)$, and the results of the second pitcher are pectoral (41\%-109\%), hamstring (164\%-86\%), and inner quadriceps (55\%-57\%).

\section{DISCUSSION}

There is an interesting finding on the activities of pectoralis muscles either for the first or the second pitcher shows that the EMG sensor of the left pectoralis muscle activities has high percentage (122\% and 109\%). This result contradicts with the fact that the pitchers used their hands when performing windmill pitching. On hamstring muscle, the maximum performance was at $150 \%$ and $164 \%$ which is in line with the fact showing that right hands are predominantly used when the pitchers perform windmill pitching which trigger the use of muscles starting from the big ones to the small ones. It has been also shown from the data that inner quadriceps play an important role during windmill pitching. The description of big muscle activity analysis in this study shows that windmill pitching triggers muscles so that trainers easily apply the training portion and program arrangement based on the description. If this this applies, pitchers will be able to avoid injury which will open more doors to maximum achievement.

\section{CONCLUSION}

This study concluded that implementing the sensor can possibly avoid the risks of injury in windmill pitching. One of the limitations of this study is lack of comprehensive description of the muscular activities. However, description of each segment of the muscles is important. It is recommended that further researchers study the description of the muscle activities per segment and relate it to the results of pitching so that there will be optimal prediction of the measurement of the muscle activities and pitching performance.

\section{REFERENCES}

[1] T. Harding, "Coaching Fastpitch Pitchers. Tanya Harding Enterprises Pty Ltd.," [Online]. Retrieved from: www.tanyaharding.com.au Access from: 2010.

[2] S.L. Werner, J.A. Guido, R.P. McNeice, J.L. Richardson, N.A. Delude, and G.W. Stewart, "Biomechanics of youth windmill softball pitching," Am J Sports Med, vol. 33, pp. 552-560, 2005.

[3] S. Barrentine, G. Fleisig, J. Whiteside, R.F. Escamilla and J.R. Andrews, "Biomechanics of windmill softball pitching with implications about injury mechanisms at the shoulder and elbow," J Ortho Sports Phys Ther, vol. 28, pp.405-415, 1998. 
[4] S.L. Werner, D.G. Jones, J.A. Guido and M.E. Brunet, "Kinematics and kinetics of elite windmill softball pitching," Am J Sport Med, vol. 34, pp. 597-603, 2006.

[5] D. Argo, S.W. Trenhaile, F.H. Savoie, L.D. Field, "Operative treatment of ulnar collateral ligament insufficiency of the elbow in female athletes.” Am J Sports Med. Vol. 34, pp. 431-437, 2006.

[6] J.L. Hill, B. Humphries, T. Weidner, R.U. Newton, "Female collegiate windmill pitchers: influences to injury incidence," J Strength Cond Res. Vol. 18, pp. 426-431, 2004.

[7] M.C. Meyers, B.R. Brown, J.A. Bloom, "Fast pitch softball injuries," Sports Med. Vol. 31, pp. 61-73, 2001.
[8] S. Tanabe, J. Nakahira, E. Bando, H. Yamaguchi, H. Miyamoto, A Yamamoto, "Fatigue fracture of the ulna occurring in pitchers of fastpitch softball," Am J Sports Med. Vol. 19, pp. 317-321, 1991.

[9] S.L. Werner, D.G. Jones, J.A. Guido, M.E. Brunet, "Kinematics and kinetics of elite windmill softball pitching," Am J Sports Med. Vol. 34, pp. 597-603, 2006.

[10] M.W. Maffet, F.W. Jobe, M.M. Pink, J. Brault, W. Mathiyakom, "Shoulder muscle firing patterns during the windmill softball pitch," Am J Sports Med. Vol. 25, no. 3, pp. 369-374, 1997. 